\title{
STATIC ANALYSIS OF MASTER LEAF SPRING
}

\author{
V.R.Baviskar ${ }^{1}$, P.L.Sarode ${ }^{2}$, I.N. Wankhede ${ }^{3}$, N.P.Salunke ${ }^{4}$ \\ ${ }^{1}$ PG Student, Mechanical Department, RCPIT Shirpur, Maharashtra, India \\ ${ }^{2}$ Assistant Professor, Mechanical Department, RCPIT Shirpur, Maharashtra, India \\ ${ }^{3}$ PG Student, Mechanical Department, RCPIT Shirpur, Maharashtra, India \\ ${ }^{4}$ H.O.D, Mechanical Department, RCPIT Shirpur, Maharashtra, India
}

\begin{abstract}
Leaf springs are one of the frequently used oldest suspension components. They are used in conventional and commercial vehicles. The past literature review shows that leaf springs are designed as forces are generalized on the elements where orientation of the axle mounting gives the reaction forces in the chassis attachment Positions. Modelling is done using CATIA V5R19 and Analysis is done by using ANSYS14.0 software. This paper describes static analysis of conventional structural steel leaf spring (master leaf) with support plate provided at the centre of leaf. Also the provision of change in eye section area is made.
\end{abstract}

Keywords: Master leaf, Geometric modelling, Static analysis.

\section{INTRODUCTION}

In automobile sector the competition is increases by modifying the existing products by new and advanced material products, for this innovation in automobile sector is responsible. Leaf spring absorbs vertical vibration and impacts due to load irregularities, means variation in the spring deflection show that potential energy is stored in spring as strain energy and then release slowly, so that increasing energy stored capability of a leaf spring insure a more flexible suspension system [1, 2, 3].In the present scenario, to optimizes the utilisation of energy and strength of master leaf.

This paper mainly focused on to reduced the stress concentration on the eye section and on whole body by increasing cross section of leaf spring. Many of the researches focused on improving fatigue resistance by shoot penning process and making the nucleation. Few publication, which are listed in references attempted static analysis of master leaf with graduated leaves and predictions of fatigue life from stress approach model. In all Industries the fatigue durability testing of the mechanical structure is performed, it is one of the parts in design process in the real application. The fatigue loading services i.e. stresses on a car wheel, bending moment on stub axle of a car, stresses on rear axle passenger car etc [2].

In many automobile components fatigue failure is the predominant mode of in-service failure. This is due to the automobile components are subjected to variety of fatigue loads such as shocks caused due to road irregularities, traced by the road wheels, the sudden loads due to the bumps on road etc. The leaf springs are more affected due to fatigue loads, as they are a part of the un-sprung mass of the automobile.[4]

\section{MODELLING OF LEAF SPRING}

In the Multi leaf structure leaf spring many problems occurs such as producing squeaking sound, fretting corrosion thereby decreasing the fatigue life.[4] The main objective of the given work is to design and analyze master leaf spring under different shape modification. For this purpose, master leaf springs is modelled in CATIA V5R19, Then analysed for static load conditions in ANSYS 14.

In the present work, only master leaf springs with different thickness and width designs are analyzed and are compared for total deformation and for stresses.

\section{MATERIAL}

The materials of structural steel behaviour characteristics related to spring performance are first determined. The effect of component processing on these characteristics is then documented followed by a demonstration of the application of these concepts to component fatigue life of particulars concern in fatigue problems is the tendency for material properties to change as a result of cyclic deformation. [2,5] Leaf spring absorbed the vertical vibrations, shocks and bumps loads (induced due to road irregularities) by means of spring deflection. So, the potential energy stored in the leaf spring and then released slowly. Ability to store and absorb more amount of strain energy insures the comfortable suspension system.[2]

Table 1: The material properties of structural steel

\begin{tabular}{|l|l|l|}
\hline 1 & Compressive Yield Strength $(\mathrm{MPa})$ & 250 \\
\hline 2 & Tensile Yield Strength $(\mathrm{MPa})$ & 250 \\
\hline 3 & Tensile Ultimate Strength $(\mathrm{MPa})$ & 460 \\
\hline
\end{tabular}




\section{ANALYTICAL CALCULATIONS:}

Following parameters are considered for design of leaf spring: -

Material - structural Steel, Tensile strength $=250 \mathrm{~N} / \mathrm{mm} 2$, Yield strength $=250 \mathrm{~N} / \mathrm{mm} 2,[6]$ Young's modulus E $=2.1 \mathrm{E} 5$ $\mathrm{N} / \mathrm{mm} 2$, Total length $=L=1010 \mathrm{~mm}$, the camber height $=$ $125 \mathrm{~mm}$, spring rate $=31.98 \mathrm{~N} / \mathrm{mm}$, [1] Normal static loading $=1230 \mathrm{~N}$, Available space for spring width $=45 \mathrm{~mm}$, thickness at centre $18 \mathrm{~mm}$ and at the end $10 \mathrm{~mm}$.

Leaf springs (also known as flat springs) are made up of flat plates. Consider a single flat plate fixed at one end and load can applied other end. This plate may be used as a flat spring.[1]

We know that the maximum bending moment in the centre,

$$
M=W \cdot L
$$

And Section modulus is

$$
Z=\frac{b t^{2}}{6}
$$

Bending stress,

$$
\sigma=\frac{M}{Z}
$$

Therefore,

Bending stress is,

$$
\sigma=\frac{(6 W \cdot L)}{b t^{2}}
$$

Now maximum deflection at the centre of the beam is

$$
\partial=\frac{W L^{3}}{3 E I}[1]
$$

\subsection{Geometric Models:}

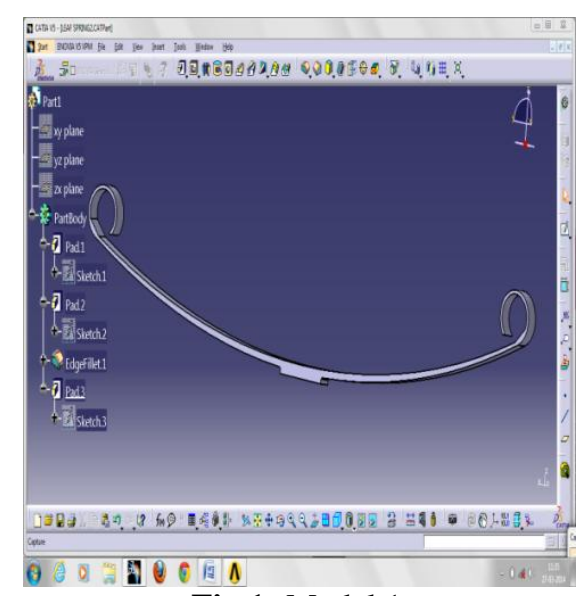

Fig 1: Model 1

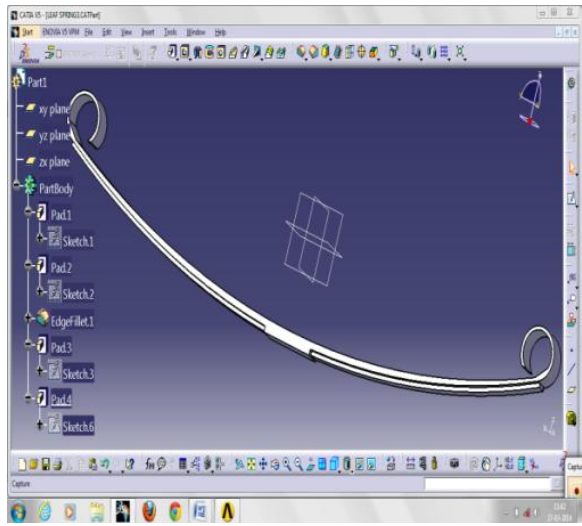

Fig 2: Model 2

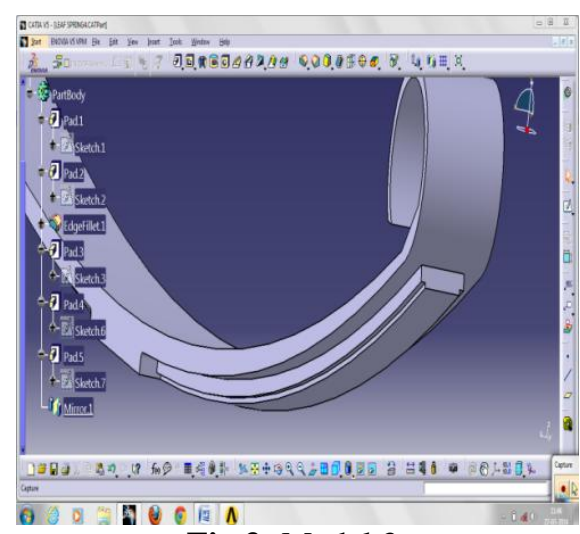

Fig 3: Model 3

\section{STATIC ANALYSIS}

For the above given specification of the leaf spring, the static analysis is performed using ANSYS 14

\subsection{Boundary Conditions}

The leaf spring is mounted on the axle of the vehicles; the ends of the leaf spring are in eye shape and the frame of the vehicle is connected to that ends. The front eye of the leaf spring is coupled with a pin to the frame therefore the eye can rotate freely about that pin but translation of front eye does not occurred. [1] The shackle is fixed to the frame of vehicle and on that shackle the rear eye of the leaf spring is connected means this link is fixed.

\section{RESULTS AND DISCUSSION}

The total deformation and von-misses stresses are calculated by using Ansys 14 for three different models.

Table 2: Total Deformation ( $\mathrm{mm})$

\begin{tabular}{|l|l|}
\hline \multicolumn{2}{|c|}{ Total Deformation (mm) for load 1230N } \\
\hline & ANSYS \\
\hline Model 1 & 83.581 \\
\hline Model 2 & 27.717 \\
\hline Model 3 & 18.072 \\
\hline
\end{tabular}




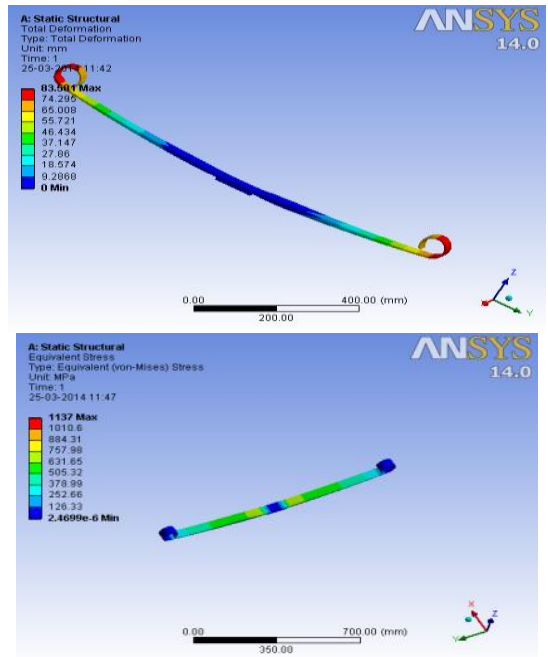

Fig 4: Total deformation and Von-misses stress (Model 1)

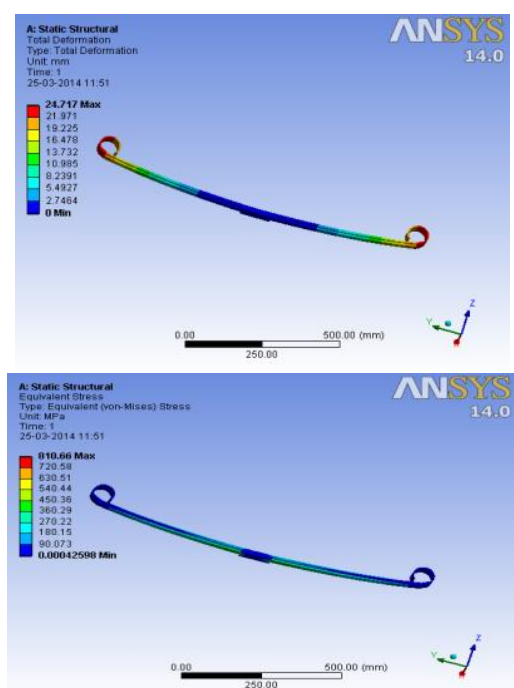

Fig 5: Total deformation and Von-misses stress (Model 2)

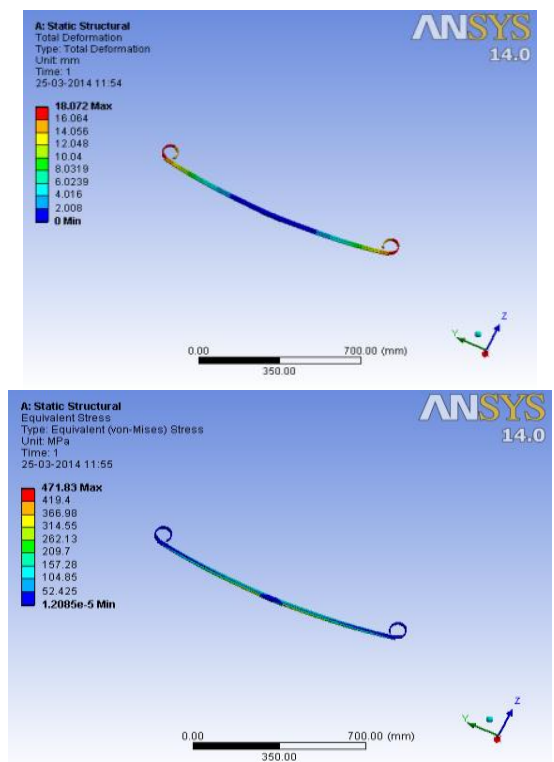

Fig 6: Total deformation and Von-misses stress (Model 3)
Table 3: Von-misses Stress $\left(\mathrm{N} / \mathrm{mm}^{2}\right)$

\begin{tabular}{|l|l|}
\hline \multicolumn{2}{|c|}{$\begin{array}{l}\text { Von-misses Stress }\left(\mathrm{N} / \mathrm{mm}^{2}\right) \text { for load } \\
1230 \mathrm{~N}\end{array}$} \\
\hline & ANSYS \\
\hline Model 1 & 1137 \\
\hline Model 2 & 810.76 \\
\hline Model 3 & 471.83 \\
\hline
\end{tabular}

\section{CONCLUSIONS}

The chassis is Located on the axles, not directly but with same form of leaf springs. The function of leaf spring in automobile is to performs the function of isolating the automobile from the road shocks. Leaf spring is a device which is used in suspension system to safeguard the vehicle and the Travellers from the road shocks which transmitted to the vehicle components and provide safe and comfortable riding, Therefore in the present work, leaf spring is modelled by CATIA VSR5 19 and static analysis is carried out by using \& ANSYS14 software and it is concluded that for the given specifications of the leaf spring, The total deformation and von-misses stresses are maximum at eye section for model 1 is $1137 \mathrm{~N} / \mathrm{mm}^{2}$ and minimum for model 3 is $471.83 \mathrm{~N} / \mathrm{mm}^{2}$.

\section{REFERENCES}

[1]. G harinath gowd and E venugopal goud "Static analysis of leaf spring" International Journal of Engineering Science and Technology (IJEST).

[2]. Zoman Digambar B, Jadhav Mahesh V, R R Kharde \& Y R Kharde "FEA Analysis of Master Leaf Spring" International Journal of Mechanical Engineering (IJME) ISSN 2319-2240Vol. 2, Issue 1, Feb 2013, 51-58 @ IASET. [3]. M Senthil Kumar And Vijayarangan "Static analysis and fatigue life prediction of steel and composite leaf spring for Light passenger vehicles" Journal of scientific and Industries Research vol 66, February 2007, pp 128 -134.

[4]. Ravi Kumar V and R. Lalitha Narayana "Analysis of Natural Fibres Composite Leaf Spring” International Journal of Latest Trends in Engineering and Technology (IJLTET).

[5]. R. W. Landgraf and R.C.Francis, "Material and Processing Effects on Fatigue Performance of Leaf Springs". Congress and Exposition Cobo Hall, Detroit February 26-March 2, 1979.

\section{BIOGRAPHIES}

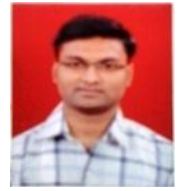

Mr. Vilas R. Baviskar. P.G Student, Mechanical Department, R.C. Patel Institute of Technology, Shirpur

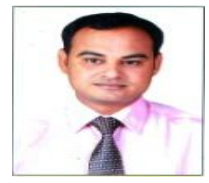

Mr. P.L. Sarode. Assistant Professor, Mechanical Department, R.C.Patel Institute of Technology, Shirpur 
Mr. Indrajit N. Wankhede P.G Student, Mechanical Department, R.C. Patel Institute of Technology, Shirpur

Mr. N.P. Salunke. H.O.D Mechanical Department, R.C.Patel Institute of Technology, Shirpur 